\title{
Loss of Heterozygosity at 12q14-15 Often Occurs in Stage I Soft Tissue Sarcomas and Is Associated with MDM2 Amplification in Tumors at Various Stages
}

Helge Taubert, Ph.D., Katja Schuster, M.S., Ulrich Brinck, M.D., Frank Bartel, Ph.D., Matthias Kappler, M.S., Christine Lautenschläger, Ph.D., Matthias Bache, Ph.D., Cornelia Trump, Hannelore Schmidt, Ph.D., Hans-Jürgen Holzhausen, M.D., Peter Würl, M.D., Thilo Schlott, Ph.D. Institute of Pathology, Martin Luther University Halle-Wittenberg (HT, KS, FB, MK, HS, JH), Halle; Institute of Medical Epidemiology, Biometry and Medical Informatics (CL) and Department of Radiotherapy, University of Halle-Wittenberg (MB), Halle; Institute of Pathology, Department of Gastroenteropathology (UB) and Institute of Pathology, Department of Cytopathology (CT, TS), GeorgAugust-University of Göttingen, Göttingen; and Surgical Clinic, University of Leipzig, Leipzig (PW), Germany

Few studies have investigated the loss of heterozygosity and microsatellite instability in soft tissue sarcomas. Therefore, we analyzed samples of human soft tissue sarcomas to determine the status of the chromosomal region 12q14-15, which contains the MDM2 gene encoding the well-known counterpart of the tumor suppressor p53. In addition, we determined whether an amplified MDM2 gene was present in the samples. Of the 88 soft tissue sarcoma samples, 24 (27\%) showed evidence of loss of heterozygosity of markers representing 12q14-15, and 12 (14\%) showed evidence of microsatellite instability. Of the 72 samples analyzed by semiquantitative polymerase chain reaction, $15(21 \%)$ possessed an amplified $M D M 2$ gene. Loss of heterozygosity $(P=$ .008) and microsatellite instability $(P=.035)$ were significantly more common in Stage I tumors than in higher stage tumors. This result indicated that these alterations occur early in soft tissue sarcoma progression and possibly define a subgroup of soft tissue sarcoma. Surprisingly, MDM2 amplification in soft tissue sarcoma patients was associated with a prognosis better than that of patients without the amplification; however, this difference was not statistically significant $(P=.6)$. Furthermore, of the

\footnotetext{
Copyright (C) 2003 by The United States and Canadian Academy of Pathology, Inc.

VOL. 16, NO. 11, P. 1109, 2003 Printed in the U.S.A.

Date of acceptance: August 15, 2003.

This work was supported by a grant from the Deutsche Krebshilfe "Miltred Scheel Stiftung” (Project No. 10-1728), Germany.

Present affiliations: Department of Molecular Pharmacology, St. Jude Children's Research Hospital, Memphis, TN (KS) and Clinic of General and Transplantation Surgery, University of Ulm, Ulm, Germany (PW). Address reprint requests to: Helge Taubert, Ph.D., Institute of Pathology, Faculty of Medicine, University Halle-Wittenberg, Magdeburger Strasse 14 D-06097 Halle/Saale, Germany; fax: 49-345-5571295; e-mail: helge.taubert@medizin.uni-halle.de.

DOI: 10.1097/01.MP.0000096045.51700.66
}

tumors with an MDM2 amplification, $40 \%(6 / 15)$ also experienced loss of heterozygosity at 12q14-15; in contrast, only $16 \%$ of tumors without an MDM2 amplification (9/57) underwent a loss of heterozygosity. A concomitant occurrence of deletions and amplifications resulting from deficiencies in the nonhomologous end-joining pathway could in part explain this finding.

KEY WORDS: Gene amplification, Loss of heterozygosity, MDM2, Microsatellite instability, Nonhomologous end joining, Soft tissue sarcoma.

Mod Pathol 2003;16(11):1109-1116

The chromosomal region $12 \mathrm{q} 13-\mathrm{q} 15$ is often affected by translocations and amplifications in soft tissue sarcoma in humans (1-9). This region includes several genes that appear to be important in tumorigenesis: cyclin-dependent kinase 4 (CDK4), sarcoma-amplified sequence (SAS), glioma-associated oncogene homolog (GLI), $\mathrm{C} / \mathrm{EBP}$-homologous protein $(\mathrm{CHOP}$; same as DDIT3 and GADD153), and the mouse double minute 2 (MDM2) $(1,3,10)$. The most studied gene in this region is likely MDM2; the wellknown counterpart of the MDM2 protein is the tumor suppressor p53. MDM2 was first localized to $12 \mathrm{q} 13-\mathrm{q} 14$ by analysis of human-hamster somatic cell hybrids by Oliner and coworkers (11). The location of MDM2 was refined by fluorescence in situ hybridization to 12q14.3-q15 distal to CDK4 (12 and Fig. 1).

Several reports have described MDM2 amplification in soft tissue sarcoma $(8,9,13)$. Interestingly, the rate of $M D M 2$ gene amplification in gliomas has been correlated with the loss of heterozygosity at loci proximal and distal to the amplification site (4). 


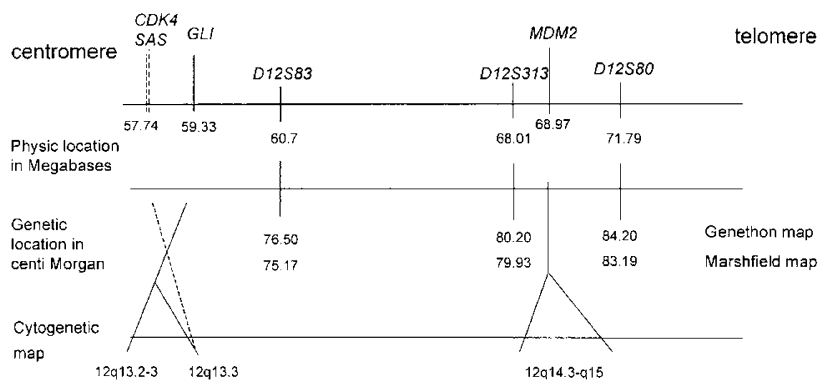

FIGURE 1. Location of the microsatellite markers and MDM2. Location of CDK4 gene and SAS gene is crossing the location of GLI gene between the physical location and the cytogenetic map. Therefore it is marked by a dashed line.

However, only one report has described the occurrence of loss of heterozygosity and microsatellite instability in 12q13-22 in soft tissue sarcoma, and the microsatellite markers that were investigated were not close to the MDM2 locus (14). Therefore, we have performed studies to investigate the occurrence of MSI and loss of heterozygosity at 12q14-15 and their relationship to $M D M 2$ amplification in soft tissue sarcoma. The microsatellite markers used in our study were D12S80 and D12S83, which flank MDM2, and D12S313, which resides between D12S80 and D12S83.

\section{MATERIALS AND METHODS}

\section{Patients' Characteristics and Soft Tissue Sarcoma Samples}

This study involved 88 tumor samples from 88 adult patients who had soft tissue sarcoma and were treated between 1992 and 2000 at the Surgical Clinic 1, University of Leipzig, Leipzig, Germany, and at the Institute of Pathology, Georg-AugustUniversity in Göttingen, Germany. These tumor samples have been partially described in previous studies $(15,16)$. The tumor samples were obtained from 65 primary tumors and 23 local recurrences. Of these 88 samples, 24 were liposarcomas, 20 were malignant fibrous histiocytomas, 18 were leiomyosarcomas, 7 were synovial sarcomas, 6 were neurogenic sarcomas, 4 were fibrosarcomas, 4 were rhabdomyosarcomas, 2 were neuroblastomas, and 3 were other types (Table 1). The patients with primary tumors did not receive chemotherapy or radiotherapy. Of the 23 cases of local recurrences, 15 patients received radiotherapy, 19 patients received chemotherapy, and 14 received a combination of radio- and chemotherapy. All patients gave written informed consent to participate in the study.
Polymerase Chain Reaction for Detection of

Microsatellite Instability and Loss of

Heterozygosity at 12q14-15

We used a modified approach based on protocols described in www.ncbi.nlm.nih.gov/genome/sts (17). The polymerase chain reaction (PCR) mixture consisted of $1 \times$ PCR buffer, $\mathrm{MgCl}_{2}$ (final concentrations: $2.5 \mathrm{~mm}$ when D12S83 was analyzed, $1.5 \mathrm{~mm}$ when D12S80 was analyzed, and $1.25 \mathrm{~mm}$ when D12S313 was analyzed), 25 pmol of each of the appropriate primers (Table 2), $2.5 \mathrm{~mm}$ each dNTP, and 0.5 U Taq DNA Polymerase (Promega; Mannheim, Germany). The conditions for PCR included an incubation step at $95^{\circ} \mathrm{C}$ for 5 minutes and subsequently 35 to 40 cycles in which each cycle consisted of denaturation at $95^{\circ} \mathrm{C}$ for 1 minute, annealing at $53^{\circ} \mathrm{C}(D 12 S 313)$ and at $55^{\circ} \mathrm{C}$ (D12S83, D12S80) for 30 seconds to 1 minute, DNA synthesis at $72^{\circ} \mathrm{C}$ for 1 minute, and elongation at $72^{\circ} \mathrm{C}$ for 5 to 8 minutes. The PCR products were run in $8 \%$ polyacrylamide gels that were subsequently silver stained as previously described (18). Results were considered uninformative when the normal tissue was homozygous for the marker of interest. Microsatellite mutations were defined by the presence of novel bands after PCR amplification of DNA from tumors; these bands were not present in products obtained by amplification of DNA from corresponding normal tissue. Loss of heterozygosity was indicated by a loss of a band or by a band whose intensity was very weak. Loss of heterozygosity was also indicated by the stronger intensity of a band representing one allele and the concomitant loss of the band representing the other allele (i.e., gain and loss) (19).

\section{Semiquantitative PCR for detection of amplified MDM2}

Semiquantitative multiplex PCR was performed according to the method of Biernat et al. (20) but with a few modifications (8). In brief, we used primers for the MDM2 gene and for the prothrombin gene to amplify specific sequences within $100 \mathrm{ng}$ of genomic DNA extracted from the tumor samples and peripheral blood leukocytes of healthy volunteers (Table 2). The PCR mixture consisted of $1 \times$ PCR reaction buffer, $2.5 \mathrm{~mm}$ $\mathrm{MgCl}_{2}, 25 \mathrm{pmol}$ of each primer pair, $200 \mu \mathrm{M}$ each dNTP, and 2.5 U of HotStarTaq DNA Polymerase (Qiagen, Hilden, Germany). Thirty cycles of PCR were performed; each cycle consisted of a denaturation step at $95^{\circ} \mathrm{C}$ for 30 seconds, an annealing step at $58^{\circ} \mathrm{C}$ for 30 seconds, and a synthesis step at $72^{\circ} \mathrm{C}$ for 2.5 minutes. The PCR products were separated by electrophoresis on a $1.5 \%$ agarose gel, and the gel was stained with ethidium bromide. The stained gel was scanned, and the band 


\begin{tabular}{|c|c|c|c|c|c|}
\hline & \multicolumn{5}{|c|}{ Number of Tumor Samples with } \\
\hline & Total & $\begin{array}{c}\text { Microsatellite } \\
\text { Instability } \\
(\%)\end{array}$ & $\begin{array}{c}\text { Loss of } \\
\text { Heterozygosity } \\
\text { (\%) }\end{array}$ & Gain (\%) & $\begin{array}{c}M D M 2 \\
\text { Amplification (\%) }\end{array}$ \\
\hline Total & 88 & $12(14)$ & $24(27)$ & $3(3)$ & $15 / 72(21)$ \\
\hline \multicolumn{6}{|l|}{ sex } \\
\hline Female & 47 & $6(13)$ & $14(30)$ & $1(2)$ & $6 / 41(15)$ \\
\hline Male & 41 & $6(15)$ & $10(24)$ & $2(5)$ & $9 / 31(29)$ \\
\hline \multicolumn{6}{|l|}{ Primary or recurrent tumor } \\
\hline Primary tumor & 65 & $10(15)$ & $19(29)$ & $3(5)$ & $10 / 51(20)$ \\
\hline Recurrence & 23 & $2(9)$ & $5(22)$ & 0 & $5 / 21(24)$ \\
\hline \multicolumn{6}{|l|}{ Tumor type } \\
\hline Liposarcoma & 24 & $4(17)$ & $10(42)$ & $1(4)$ & $9 / 20(45)$ \\
\hline MFH & 20 & $3(15)$ & $5(25)$ & $1(5)$ & $2 / 16(12)$ \\
\hline Leiomyosarcoma & 18 & $3(17)$ & $6(33)$ & $1(6)$ & $2 / 14(14)$ \\
\hline Synovial sarcoma & 7 & 0 & $2(29)$ & 0 & $0 / 6$ \\
\hline \multicolumn{6}{|l|}{ Neurogenic } \\
\hline Sarcoma & 6 & $1(17)$ & $1(17)$ & 0 & $1 / 4(25)$ \\
\hline Fibrosarcoma & 4 & $1(25)$ & 0 & 0 & $1 / 4(25)$ \\
\hline Rhabdomyosarcoma & 4 & 0 & 0 & 0 & $0 / 4$ \\
\hline Neuroblastoma & 2 & 0 & 0 & 0 & $0 / 1$ \\
\hline Others & 3 & 0 & 0 & 0 & $0 / 3$ \\
\hline \multicolumn{6}{|l|}{ Tumor grade } \\
\hline I & 21 & $5(24)$ & $10(48)$ & 0 & $6 / 16(38)$ \\
\hline II & 37 & $5(14)$ & $7(19)$ & 3 & $5 / 31(16)$ \\
\hline III & 30 & $2(7)$ & $7(23)$ & 0 & $4 / 25(16)$ \\
\hline \multicolumn{6}{|l|}{ Tumor stage } \\
\hline I & 17 & $5(29)$ & $9(53)$ & 0 & 4/14 (29) \\
\hline II & 32 & $4(13)$ & $6(19)$ & $3(9)$ & $7 / 29(24)$ \\
\hline III & 23 & $2(9)$ & $5(22)$ & 0 & $1 / 23(4)$ \\
\hline IV & 16 & $1(6)$ & $4(25)$ & 0 & $3 / 6(50)$ \\
\hline \multicolumn{6}{|l|}{ Tumor size } \\
\hline $\mathrm{T} 1$ & 12 & $3(25)$ & $5(42)$ & 0 & $0 / 8$ \\
\hline $\mathrm{T} 2$ & 76 & $9(12)$ & $19(25)$ & $3(4)$ & $15 / 64(23)$ \\
\hline \multicolumn{6}{|l|}{ Lymph node involvement } \\
\hline No & 85 & $12(14)$ & $24(28)$ & $3(4)$ & $15 / 69(22)$ \\
\hline N1 & 3 & 0 & 0 & 0 & $0 / 3$ \\
\hline \multicolumn{6}{|l|}{ Metastases } \\
\hline M0 & 78 & $12(15)$ & $23(29)$ & $3(4)$ & $13 / 66(20)$ \\
\hline \multirow{2}{*}{\multicolumn{6}{|c|}{ Follow-up }} \\
\hline & & & & & \\
\hline Alive & 53 & $6(11)$ & $16(30)$ & $3(6)$ & $9 / 43(21)$ \\
\hline Dead & 35 & $6(17)$ & $8(23)$ & 0 & $6 / 29(21)$ \\
\hline Av. length of observation in months (range) & $36(4-120)$ & $37(35-120)$ & $44(14-120)$ & $32(20-52)$ & $26(11-38)$ \\
\hline Av. survival period in months (range) & $23(2-96)$ & $37(11-80)$ & $29(4-48)$ & - & $37(4-96)$ \\
\hline
\end{tabular}

Av., average.

TABLE 2. Primers Used for Multiplex Polymerase Chain Reaction and Semiquantitative Polymerase Chain Reaction

\begin{tabular}{llc}
\hline $\begin{array}{c}\text { Target } \\
\text { Microsatellite/Gene }\end{array}$ & \multicolumn{1}{c}{ Sequence of Primer } & Reference \\
\hline D12S83 & $\begin{array}{l}\text { sense 5' TTT TTG GAA GTC TAT CAA TTT GA 3' } \\
\text { antisense 5' TAG CAG AGA AAG CCA ATT CA 3' } \\
\text { s12S313 }\end{array}$ & 17 \\
sense 5' CAT CNC CAA TCT CTC CTC AGT 3' & antisense 5' CCA AAC TCA TTG ATG TCT TTA TT 3' \\
sense 5' CCA GCC TGG AAT GAT ATG TA 3' & 17 \\
antisense 5' GAA TGT CAA TGG ACC AGA TG 3' & sense 5'-GCTGACTATTGGAATGCAC-3' \\
antisense 5'-ATTGGTTGTCTACATACTGGGC-3' & sense 5'-TCATCCTCAGTCCTAATGC-3' \\
Prothrombin & antisense 5'-AGACCCAAGAAGAATGG-3' & 37 \\
\end{tabular}

intensity was measured by densitometry (ImageMaster VDS 3.0 Software; Amersham Pharmacia, Freiburg, Germany). Finally, we calculated the ratio of the intensity of the MDM2 bands to the intensity of the prothrombin band. The prothrombin (trombin) gene is located on chromo- some 11p11-q12, which should not interfere with chromosomal location of mdm2 gene. We considered any ratio $>3$ to indicate amplification of the MDM2 gene. Genomic DNA extracted from peripheral blood leukocytes of healthy volunteers served as a control. 


\section{Statistical Analyses}

We evaluated the association between tumor stage and the presence of microsatellite instability or loss of heterozygosity by using the $\chi^{2}$ test, under the assumption that their percentage distribution in each tumor stage was equal. In Kaplan-Meier analyses, the relationship between survival and the presence of MSI, loss of heterozygosity, or gene amplification was evaluated. Statistical analyses were performed with SPSS 10.0 software (SPSS, Inc., Chicago, IL).

\section{RESULTS}

\section{Analysis of Loss of Heterozygosity and Gains at} 12q14-15

Of the 88 soft tissue sarcoma samples that we analyzed, 24 (27\%) showed loss of heterozygosity at $12 q 14-15$, and 3 (3\%) showed a gain of DNA in that region. Loss of heterozygosity occurred in $42 \%$ (10/
24) of liposarcomas, $33 \%$ (6/18) of leiomyosarcomas, $29 \%(2 / 7)$ of synovial sarcomas, $25 \%(5 / 20)$ of malignant fibrous histiocytomas, and $17 \%(1 / 6)$ of neurogenic sarcomas (Tables 1 and 3; Fig. 2). No loss of heterozygosity at 12q14-15 was found in rhabdomyosarcoma (4 cases investigated), fibrosarcoma (4 cases), neuroblastoma (2 cases), or other sarcomas whose classification could not be determined (3 cases). Gains of DNA at 12q14-15 were detected in only three tumor samples: a liposarcoma, a leiomyosarcoma, and a malignant fibrous histiocytoma (Table 1 , Fig. 2). The percentage of Stage I tumors with a loss of heterozygosity $(53 \%)$ was significantly higher than that of Stage II tumors (19\%), Stage III tumors (22\%), and Stage IV tumors $\left(25 \% ; P=.008 ; \chi^{2}\right.$ test). In the Kaplan-Meier analysis, the median survival period for patients whose soft tissue sarcoma was a site of loss of heterozygosity at 12q14-15 (58 mo) was shorter than that for patients with unaffected soft tissue sarcoma (68 mo).

TABLE 3. Soft Tissue Sarcoma Samples that Experienced Loss of Heterozygosity, Microsatellite Instability in 12q1415 or MDM2 Amplification

\begin{tabular}{|c|c|c|c|c|c|c|c|}
\hline Sample & Type & $\begin{array}{l}\text { Primary (P) or } \\
\text { Recurrent (R) }\end{array}$ & Staging & D12S83 & $D 12 S 313$ & D12S80 & MDM2 Amplification \\
\hline LZ3 & LS myxoid & $\mathrm{R}$ & II & 0 & 0 & 0 & + \\
\hline LZ6 & NS & $\mathrm{R}$ & II & 0 & MSI & MSI & - \\
\hline LZ9 & LS well diff. & $\mathrm{P}$ & I & 0 & MSI & $\mathrm{LOH}$ & + \\
\hline LZ10 & LS pleom & $\mathrm{P}$ & II & 0 & 0 & MSI & - \\
\hline LZ14 & FS & $\mathrm{P}$ & I & 0 & 0 & MSI & - \\
\hline LZ17 & LS well diff. & $\mathrm{P}$ & I & $\mathrm{LOH}$ & 0 & MSI & - \\
\hline LZ25 & LS well diff. & $\mathrm{P}$ & I & 0 & 0 & 0 & + \\
\hline LZ32 & FS & $\mathrm{R}$ & II & 0 & 0 & 0 & + \\
\hline LZ35 & LMS & $\mathrm{R}$ & IV & $\mathrm{LOH}$ & $\mathrm{LOH}$ & $\mathrm{LOH}$ & - \\
\hline LZ36 & LS well diff. & $\mathrm{P}$ & I & 0 & $\mathrm{LOH}$ & 0 & + \\
\hline LZ37 & MFH & $\mathrm{R}$ & IV & LOH & 0 & $\mathrm{LOH}$ & + \\
\hline LZ45 & MFH & $\mathrm{R}$ & IV & 0 & 0 & MSI & n.d. \\
\hline LZ46 & NS & $\mathrm{P}$ & II & LOH & 0 & 0 & + \\
\hline LZ48 & LS well diff. & $\mathrm{P}$ & II & 0 & 0 & 0 & + \\
\hline LZ54 & LMS & $\mathrm{P}$ & III & 0 & 0 & $\mathrm{LOH}$ & + \\
\hline LZ56 & LS round cell & $\mathrm{R}$ & IV & 0 & 0 & $\mathrm{LOH}$ & n.d. \\
\hline LZ59 & LS well diff. & $\mathrm{P}$ & II & 0 & 0 & $\mathrm{LOH}$ & + \\
\hline LZ63 & LMS & $\mathrm{P}$ & II & 0 & LOH & 0 & n.d. \\
\hline LZ68 & MFH & $\mathrm{P}$ & III & 0 & 0 & MSI & - \\
\hline LZ72 & MFH & $\mathrm{P}$ & III & $\mathrm{LOH}$ & 0 & 0 & - \\
\hline LZ76 & LMS & $\mathrm{P}$ & II & 0 & 0 & 0 & + \\
\hline LZ81 & LS well diff. & $\mathrm{R}$ & I & 0 & $\mathrm{LOH}$ & 0 & + \\
\hline LZ82 & LS myxoid & $\mathrm{P}$ & II & 0 & 0 & 0 & + \\
\hline LZ85 & LS myxoid & $\mathrm{R}$ & IV & 0 & 0 & 0 & + \\
\hline LZ86 & LS well diff. & $\mathrm{P}$ & I & 0 & $\mathrm{LOH}$ & $\mathrm{LOH}$ & - \\
\hline LZ94 & SS & $\mathrm{P}$ & II & $\mathrm{LOH}$ & 0 & 0 & - \\
\hline LZ99 & MFH & $\mathrm{P}$ & IV & LOH & LOH & $\mathrm{LOH}$ & - \\
\hline LZ100 & MFH & $\mathrm{P}$ & IV & 0 & 0 & 0 & + \\
\hline LZ101 & LMS & $\mathrm{P}$ & II & 0 & 0 & Gain & - \\
\hline LZ102 & LMS & $\mathrm{P}$ & III & 0 & 0 & $\mathrm{LOH}$ & - \\
\hline G2 & LMS & $\mathrm{P}$ & I & 0 & $\mathrm{LOH}$ & MSI & n.d. \\
\hline G4 & LMS & $\mathrm{P}$ & II & LOH & $\mathrm{LOH}$ & MSI & n.d. \\
\hline G12 & MFH & $\mathrm{P}$ & II & 0 & Gain & $\mathrm{LOH}$ & n.d. \\
\hline G14 & LS myxoid/low diff. & $\mathrm{P}$ & III & 0 & $\mathrm{LOH}$ & 0 & n.d. \\
\hline G26 & MFH & $\mathrm{P}$ & III & LOH & MSI & 0 & n.d. \\
\hline G29 & LMS & $\mathrm{P}$ & II & 0 & $\mathrm{LOH}$ & MSI & n.d. \\
\hline G35 & LS myxoid & $\mathrm{P}$ & I & 0 & MSI & $\mathrm{LOH}$ & n.d. \\
\hline G46 & LS myxoid & $\mathrm{P}$ & I & 0 & $\mathrm{LOH}$ & 0 & n.d. \\
\hline
\end{tabular}

P, primary tumor; R, recurrence; FS, fibrosarcoma; LS well diff, well differentiated liposarcoma; LS low diff, low differentiated liposarcoma; LS pleom, pleomorphic liposarcoma; LMS, leiomyosarcoma; MFH, malignant fibrous histiocytoma; NS, neurogenic sarcoma; SS, synovial sarcoma; n.d., not determined. 


\section{LZ 98 LZ99 LZ100 LZ101 LZ102

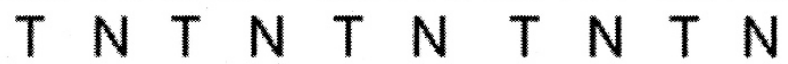

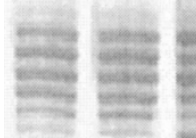

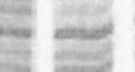

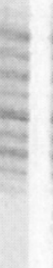

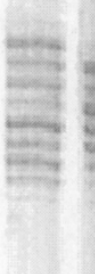

FIGURE 2. STS samples with loss of heterozygosity or gain in microsatellite marker D12S80 visualized in a silver-stained polyacrylamide gel. LZ98 and LZ100 represent samples without changes. In Samples LZ99 and LZ102, loss of heterozygosity was detected (note a gain in intensity of upper bands and a loss of intensity in lower bands between normal tissue $[\mathrm{N}]$ and tumor tissue $[\mathrm{T}]$ in Sample LZ99). In Sample LZ101 a gain was identified.

Analysis of Microsatellite Instability at 12q14-15

We found instability at one microsatellite sequence marker in 12 (14\%) of the 88 soft tissue sarcoma samples, but only in one was instability at two markers observed (Table 3). Microsatellite instability occurred in 4 (17\%) of the 24 liposarcomas, $3(17 \%)$ of the 18 leiomyosarcomas, and in $3(15 \%)$ of the 20 malignant fibrous histiocytomas, but no MSI was found in synovial sarcoma (7 cases investigated), rhabdomyosarcoma (4 cases), neuroblastoma (2 cases), or other sarcomas whose classification could not be determined ( 3 cases; Table 1). The high percentages of MSI in fibrosarcomas ( 1 of 4; $25 \%$ ) and neurogenic sarcomas (1 of $6 ; 17 \%$ ) are based on a small number of cases investigated.

MSI occurred significantly more often in Stage I tumors $(29 \%)$ than in Stage II tumors (13\%), Stage III tumors $(9 \%)$, and Stage IV tumors $(6 \% ; P=.035$, $\chi^{2}$ test). The Kaplan-Meier analysis showed that the median survival period for patients whose soft tissue sarcoma contained MSI at 12q14-15 was less than that for patients with unaffected soft tissue sarcoma (58 months compared with 68 months).

\section{MDM2 Amplification}

We performed semiquantitative PCR to determine whether the MDM2 gene was amplified in 72 of the 88 tumor samples. DNA from 16 tumor samples was inadequate for semiquantitative PCR. Amplification of MDM2 was detected in 15 (17\%) of the 72 samples of soft tissue sarcoma. In $45 \%$ of the liposarcomas, we found the amplification, whereas the amplification occurred in only $14 \%$ of leiomyosarcomas and $12 \%$ of malignant fibrous histiocytomas (Tables 1 and 3). The high percentage of neurogenic sarcoma and fibrosarcoma (each $25 \%$; each $1 / 4$ ) with the amplification are based on a small number of cases investigated. No amplifications were detected in samples of synovial sarcoma (6 samples), rhabdomyosarcoma (4 samples), neuroblastoma (1 sample), or other sarcomas whose classification could not be determined (3 samples). Patients whose tumors possessed an MDM2 gene amplification had a longer median survival period (68 mo) than did those whose tumors lacked the amplification (32 mo; data not shown). There was no association between the occurrence of MDM2 amplification and tumor stage.

\section{DISCUSSION}

The percentage of soft tissue sarcoma samples with loss of heterozygosity at the chromosomal region $12 q 14-15(27 \%)$ was in the range of $3 \%$ to $57 \%$ reported for soft tissue sarcoma, with loss of heterozygosity at other chromosomal regions $(6,7,14$, 19, 21-23). However, the occurrence of loss of heterozygosity may depend on the type of tumor and the microsatellite markers that are analyzed. Loss of heterozygosity at 12q14-15 was most common in liposarcoma samples: 10 (42\%) of the 24 samples were marked by loss of heterozygosity. This percentage corresponds to the findings of SchneiderStock et al. $(6,7)$, who identified loss of heterozygosity in other chromosomal regions in $22 \%$ and $39 \%$ of liposarcoma samples in two studies. Such loss of heterozygosity was detected in myxoid liposarcoma and pleomorphic liposarcoma but not in well-differentiated liposarcoma. In contrast, six of the nine samples of well-differentiated liposarcoma in our study had undergone loss of heterozygosity at 12q14-15, and the single sample of pleomorphic liposarcoma that we investigated did not possess a loss of heterozygosity.

In the present study, loss of heterozygosity occurred in $33 \%$ of leiomyosarcoma samples (6/18), a percentage that is in within the range of other reports $(22,24)$. Few studies of the prevalence of loss of heterozygosity in other types of soft tissue sarcoma have been reported $(14,19,23)$.

The number of soft tissue sarcoma samples in which MSI at $12 q 14-15$ occurred $(12 / 88 ; 14 \%)$ was relatively low. This finding is in accord with other reported results regarding the prevalence of MSI at all regions in soft tissue sarcoma. Therefore, it has been suggested that the occurrence of MSI in any analyzed region plays no major role in the genesis of soft tissue sarcoma and has no considerable impact on the prognosis of patients with soft tissue sarcoma $(7,23-26)$.

The percentage of soft tissue sarcoma samples with an MDM2 gene amplification in this study $(21 \%)$ is very similar to that reported in the MDM2 amplification database (20\%) (13). The amplification occurred most often in liposarcomas (45\%); however, this percentage exceeds that in the data- 
base (29\%). This discrepancy might be due to the higher proportion of well-differentiated liposarcoma samples in our study. This subtype of liposarcoma has frequently associated with MDM2 amplification $(6,27,28)$. The present paper is the first to report the presence of MDM2 amplification in leiomyosarcoma (2 samples); no other examples have yet been deposited in the MDM2 amplification database. However, in studies performed by comparative genomic hybridization, high-level amplifications of the 12q14-15 region could be found in leiomyosarcomas. Recently, in malignant fibrous histiocytoma, a subgroup was identified that carried these chromosomal aberrations, reminiscent of well-differentiated liposarcoma or leiomyosarcoma. The investigators suggested that malignant fibrous histiocytomas are a morphologic modulation in the tumoral progression of other sarcomas, particularly LMS $(29,30)$.

It was remarkable that the occurrence of loss of heterozygosity and of MSI was significantly more common in Stage I tumors $(P=.008$ and .035 , respectively) than in tumors at other stages. Our result is supported by the earlier finding of loss of heterozygosity at regions other than $12 q 14-15$ in a high number of low-grade soft tissue sarcoma of the extremities (19). This finding suggests that MSI and loss of heterozygosity at 12q14-15 may occur early in tumor development and supports the hypothesis that MSI and gene deletions are early events in tumor progression (31). The less frequent occurrence of loss of heterozygosity and MSI at 12q14-15 in tumors at Stages II, III, or IV indicates that Stage I tumors and tumors at the other stages may differ in their origin and behavior. The Stage I tumors with loss of heterozygosity and MSI at 12q14-15 may represent a separate group of the soft tissue sarcoma. Furthermore, two groups of tumors may exist: one with a diploid phenotype and a defective mismatch repair system that leads to MSI and a second group that exhibits aneuploidy, loss of heterozygosity, small mutations in tumor suppressor genes and oncogenes, and an absence of MSI (19). This hypothesis is supported by the findings of p53 mutations in the soft tissue sarcoma samples and the significant correlation between p53 mutation and poor prognosis of patients with soft tissue sarcoma (32 and our unpublished results). Of the 88 tumor samples in the present study, 50 were investigated to determine whether any p53 mutation was present. Six carried a p53 mutation (LZ1, LZ13, LZ23, LZ33, LZ35, LZ56), and the mutation was correlated with a prognosis that was worse than that of patients without the p53 mutation (data not shown).

There was a correlation between the occurrence of loss of heterozygosity at 12q14-15 and MDM2 amplification. In $6(40 \%)$ of the 15 tumor samples with an MDM2 amplification, loss of heterozygosity at 12q14-15 occurred; however, only in 9 of the 57 tumor samples without an MDM2 amplification was loss of heterozygosity detected. Similar results concerning gliomas were reported by Reifenberger et al. (4). They found that $50 \%$ of gliomas with an MDM2 amplification also had loss of heterozygosity in $12 q 13-14$, whereas only $16 \%$ of the gliomas without an MDM2 amplification had experienced loss of heterozygosity.

What might be the reason for a concomitant occurrence of MDM2 amplification and loss of heterozygosity at $12 \mathrm{q} 14-15$ ? Recent results concerning the nonhomologous end-joining (NHEJ) pathway may explain at least in part this phenomenon in soft tissue sarcoma. The NHEJ system repairs double-strand DNA breaks. The pathway consists of the following components: DNA ligase IV, Xrcc4, Artemis, and the DNA-dependent protein kinase (DNA-PK), which itself is composed of Ku70, Ku80, and the kinase catalytic subunit DNA-PKcs (33). Deficiencies in this pathway result in gene amplification, deletion, and translocation. Hoon Cho and coworkers (19) described the loss of heterozygosity of DNA-PK genes in low-grade soft tissue sarcoma. Moreover, the survival probability of patients with loss of heterozygosity of the DNA-PKcs gene was significantly lower than that of patients without loss of heterozygosity of this gene $(P=.016)$. Our hypothesis is also supported by findings that the lack of Ku80 accelerates the formation of tumors, especially lymphomas and sarcomas, in $p 53^{+/-}$mice (34). Furthermore, mice heterozygous for the DNA ligase IV gene (Ink4a/Arf ${ }^{-1-}$-background) develop more soft tissue sarcoma that possess clonal amplifications, deletions, and translocations than do mice homozygous for the wild-type gene (same genetic background). In 3 of the 12 Lig4 $^{+/-}$Ink4a/ $\mathrm{Arf}^{-1-}$-tumors, amplification of the $\mathrm{Mdm} 2$ gene was detected, but none of the eight $\operatorname{Lig}^{+} / \operatorname{Lig}^{+}$ Ink $4 \mathrm{a}^{-} / \mathrm{Arf}^{-1-}$-tumors possessed this abnormality (33). Investigation of the components of the NHEJ system may give insight into the molecular basis of loss of heterozygosity at 12q14-15 and MDM2 amplification.

We confirmed our previously reported result that an amplification of $M D M 2$ in soft tissue sarcoma is associated with a prognosis better than that associated with soft tissue sarcoma that lacks the amplification (8). However, this finding might be specific for liposarcoma. MDM2 amplification seems to be characteristic of well-differentiated liposarcoma $(6,27,28)$, a subtype associated with a prognosis better than that associated with other subtypes of liposarcoma (35). Furthermore, Pilotti et al. (27) reported that amplicons at $12 \mathrm{q} 13-22$, which do not include MDM2, may contribute to transformation in non-retroperitoneal well-differentiated liposar- 
coma. They support the role of CDK4 in opposing p53 function, particularly in this tumor type (27). However, the question of whether the better prognosis of soft tissue sarcoma patients with mdm2 gene amplifications is caused mostly by welldifferentiated liposarcomas has to be investigated in larger patient groups.

There are also indications that the MDM2 oncogene possesses a normal physiologic function in growth inhibition and apoptosis (36). Amplification of various genes is thought to occur late in tumor progression and might be an event secondary to deletion (31). This statement also seems true for the MDM2 amplification, because this amplification did not occur more often in Stage I tumors than in tumors at other stages. In stages besides Stage I, MDM2 amplification may balance the detrimental effects resulting from the loss of the MDM2 gene that can be deleted at the beginning of tumor development. Another possibility is that MDM2 amplification occurs as a part of an amplification of a longer chromosomal region, which can include other genes such as CDK4, GLI, SAS, or CHOP (1, 3 10). Furthermore, reports have described amplifications of the 12q13-15 region in the absence of an amplified MDM2 gene $(1,5)$, and the amplification of MDM2 alone is less common than its amplification with other genes such as $S A S$ or $C D K 4(1,3,26)$.

In summary, we found that loss of heterozygosity and MSI at 12q14-15 occur more often in Stage I tumors than in tumors at other stages. MDM2 amplification in soft tissue sarcoma was associated with a longer median survival period than was the absence of $M D M 2$ amplification. Finally, MDM2 amplification was associated with loss of heterozygosity at 12q14-15 in soft tissue sarcoma.

Acknowledgment: The authors thank Mrs. B. Wypior for excellent technical assistance and Dr. W. Dietmaier for the kind introduction into the field of MSI and loss of heterozygosity investigation. The authors are very grateful to the Scientific Editing Department of St. Jude Children's Research Hospital in Memphis for excellent revision of the manuscript.

\section{REFERENCES}

1. Forus A, Florenes VA, Maelandsmo GM, Meltzer PS, Fodstad $\mathrm{O}$, Myklebost O. Mapping of amplification units in the q13-14 region of chromosome 12 in human sarcomas: some amplica do not include MDM2. Cell Growth Differ 1993;4: 1065-70.

2. Leach FS, Tokino T, Meltzer P, Burrell M, Oliner JD, Smith S, et al. p53 mutation and MDM2 amplification in human soft tissue sarcomas. Cancer Res 1993;53:2231-4.

3. Nilbert M, Rydholm A, Mitelman F, Meltzer PS, Mandahl N. Characterization of the 12q13-15 amplicon in soft tissue tumors. Cancer Genet Cytogenet 1995;83:32-6.
4. Reifenberger G, Reifenberger J, Ichimura K, Collins VP. Amplification at 12q13-14 in human malignant gliomas is frequently accompanied by loss of heterozygosity at loci proximal and distal to the amplification site. Cancer Res 1995;55: 731-4.

5. Reifenberger G, Ichimura K, Reifenberger J, Elkahloun AG, Meltzer PS, Collins VP. Refined mapping of 12q13-q15 amplicons in human malignant gliomas suggests CDK4/SAS and MDM2 as independent amplification targets. Cancer Res 1996;56:5141-5.

6. Schneider-Stock R, Walter H, Radig K, Rys J, Bosse A, Kuhnen C, et al. MDM2 amplification and loss of heterozygosity at Rb and p53 genes: no simultaneous alterations in the oncogenesis of liposarcomas. J Cancer Res Clin Oncol 1998;124:53240.

7. Schneider-Stock R, Szibor R, Walter H, Plate I, Roessner A. No microsatellite instability, but frequent LOH in liposarcomas. Int J Oncol 1999;14:721-6.

8. Bartel F, Meye A, Würl P, Kappler M, Bache M, Lautenschläger $\mathrm{C}$, et al. Amplification of the MDM2 gene, but not expression of splice variants of MDM2 MRNA, is associated with prognosis in soft tissue sarcoma. Int J Cancer 2001;95: $168-75$.

9. Boltze C, Schneider-Stock R, Jager V, Roessner A. Distinction between lipoma and liposarcoma by MDM2 alterations: a case report of simultaneously occurring tumors and review of the literature. Pathol Res Pract 2001;197:563-8.

10. Pedeutour F, Suijkerbuijk RF, Forus A, Van Gaal J, Van de Klundert W, Coindre JM, et al. Complex composition and co-amplification of SAS and MDM2 in ring and giant rod marker chromosomes in well-differentiated liposarcoma. Genes Chromosomes Cancer 1994;10:85-94.

11. Oliner JD, Kinzler KW, Meltzer PS, George DL, Vogelstein B. Amplification of a gene encoding a p53-associated protein in human sarcomas. Nature 1992;358:80-3.

12. Mitchell ELD, White GRM, Santibanez-Koref MF, Varley JM, Heighway J. Mapping of gene loci in the q13-q15 region of chromosome 12. Chromosome Res 1995;3:261-2.

13. Momand J, Jung D, Wilczynski S, Niland J. The MDM2 gene amplification database. Nucleic Acids Res 1998;26:3453-9.

14. Wolf M, Aaltonen LA, Szymanska J, Tarkkanen M, Blomqvist C, Berner JM, et al. Complexity of 12q13-22 amplicon in liposarcoma: microsatellite repeat analysis. Genes Chromosomes Cancer 1997;18:66-70.

15. Kappler M, Köhler T, Kampf C, Diestelkötter P, Würl P, Schmitz $\mathrm{M}$, et al. Increased survivin transcript levels: an independent negative predictor of survival in soft tissue sarcoma patients. Int J Cancer 2001;95:360-3.

16. Würl P, Kappler M, Meye A, Bartel F, Köhler T, Lautenschläger C, et al. Co-expression of survivin and TERT and risk of tumour-related death in patients with soft-tissue sarcoma. Lancet 2002;359:943-5.

17. www.ncbi.nlm.nih.gov/genome/sts.

18. Dietmaier W, Hartmann A, Wallinger S, Heinmöller E, Kerner T, Endl E, et al. Multiple mutation analyses in single tumor cells with improved whole genome amplification. Am J Pathol 1999;154:83-95.

19. Hoon Cho N, Cordon-Cardo C, Li GC, Hyun Kim S. Allotype imbalance or microsatellite mutation in low-grade soft tissue sarcomas of the extremities in adults. J Pathol 2002;198: 21-9.

20. Biernat W, Kleihues P, Yonekawa Y, Ohgaki H. Amplification and overexpression of MDM2 in primary (de novo) glioblastomas. J Neuropathol Exp Neurol 1997;56:180-5.

21. Schneider-Stock R, Radig K, Roessner A. Loss of heterozygosity on chromosome 9q21 (p16 gene) uncommon in softtissue sarcomas. Mol Carcinog 1997;18:63-5.

22. Quade BJ, Pinto AP, Howard DR, Peters WA, Crum CP. Frequent loss of heterozygosity for chromosome 10 in uterine 
leiomyosarcoma in contrast to leiomyoma. Am J Pathol 1999;154:945-50.

23. Suwa K, Ohmori M, Miki H. Microsatellite alterations in various sarcomas in Japanese patients. J Orthop Sci 1999;4: 223-30.

24. Amant F, Dorfling CM, Dreyer L, Vergote I, Lindeque BG, Van Rensburg EJ. Microsatellite instability in uterine sarcomas. Int J Gynecol Cancer 2001;11:218-23.

25. Risinger JI, Umar A, Boyer JC, Evans AC, Berchuck A, Kunkel TA, et al. Microsatellite instability in gynecological sarcomas and in hMSH2 mutant uterine sarcoma cell lines defective in mismatch repair activity. Cancer Res 1995;55:5664-9.

26. Visser M, Bras J, Sijmons C, Devilee P, Wijnaendts LC, van der Linden JC, et al. Microsatellite instability in childhood rhabdomyosarcoma is locus specific and correlates with fractional allelic loss. Proc Natl Acad Sci U S A 1996;93: 9172-6.

27. Pilotti S, Della Torre G, Lavarino C, Sozzi G, Minoletti F, Vergani B, et al. Molecular abnormalities in liposarcoma: role of MDM2 and CDK4-containing amplicons at 12q13-22. J Pathol 1998;185:188-90.

28. Forus A, Bjerkehagen B, Sirvent N, Meza-Zepeda LA, Coindre JM, Berner JM, et al. A well-differentiated liposarcoma with a new type of chromosome 12-derived markers. Cancer Genet Cytogenet 2001;131:13-8.

29. Derre J, Lagace R, Nicolas A, Mairal A, Chibon F, Coindre JM, et al. Leiomyosarcomas and most malignant fibrous histiocytomas share very similar comparative genomic hybridiza- tion imbalances: an analysis of a series of 27 leiomyosarcomas. Lab Invest 2001;81:211-5.

30. Chibon F, Mariani O, Derre J, Malinge S, Coindre JM, Guillou L, et al. A subgroup of malignant fibrous histiocytomas is associated with genetic changes similar to those of welldifferentiated liposarcomas. Cancer Genet Cytogenet 2002; 139(1):24-9.

31. Lengauer C, Kinzler KW, Vogelstein B. Genetic instabilities in human cancers. Nature 1998;396:643-9.

32. Taubert H, Meye A, Würl P. Soft tissue sarcomas and p53 mutations. Mol Med 1998;4:365-72.

33. Sharpless NE, Ferguson DO, O'Hagan RC, Castrillon DH, Lee C, Farazi PA, et al. Impaired nonhomologous end-joining provokes soft tissue sarcomas harbouring chromosomal translocations, amplifications, and deletions. Mol Cell 2001; 8:1187-96.

34. Lim DS, Vogel H, Willerford DM, Sands AT, Platt KA, Hasty P. Analysis of ku80-mutant mice and cells with deficient levels of p53. Mol Cell Biol 2000;20:3772-80.

35. Enzinger FM, Weiss SW, General considerations. In: Enzinger FM, Weiss SW, editors. Soft tissue tumors. 3rd ed. St. Louis, MO: Mosby; 1995. p. 1-18.

36. Bartel F, Taubert H, Harris LC. Alternative and aberrant splicing of MDM2 mRNA in human cancer. Cancer Cell 2002;2:9-15.

37. Schlott T, Reimer S, Jahns A, Ohlenbusch A, Ruschenburg I, Nagel H, et al. Point mutations and nucleotide insertions in the MDM2 zinc finger structure of human tumours. J Pathol 1997;182:54-61. 